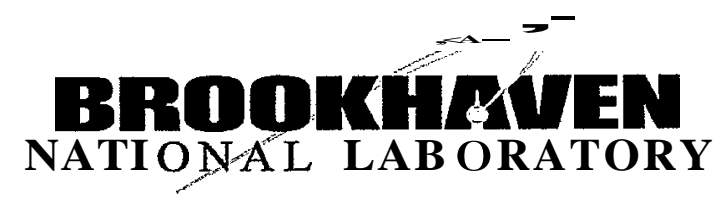

BNL-73500-2005-CP

\title{
High Energy Pulsed Power Systemfor AGS Super Neutrino Focusing Horn
}

\author{
W. Zhang, J. Sandberg, W-T. Weng \\ Presented at the Particle Accelerator Conference (PAC'05) \\ Knoxville, Tennessee \\ May 16-20, 2005
}

\author{
Collider-Accelerator Department \\ Brookhaven National Laboratory \\ P.O. Box 5000 \\ Upton, NY 11973-5000 \\ www.bnl.gov \\ Managed by \\ Brookhaven Science Associates, LLC \\ for the United States Department of Energy under \\ Contract No. DE-AC02-98CH10886
}

This is a preprint of a paper intended for publication in a journal or proceedings. Since changes may be made before publication, this preprint is made availablewith the understanding that it will not be cited or reproducedwithout the permission of the author. 


\section{DISCLAIMER}

This report was prepared as an account of work sponsored by an agency of the United States Government. Neither the United States Government nor any agency thereof, nor any of their employees, nor any of their contractors, subcontractors, or their employees, makes any warranty, express or implied, or assumes any legal liability or responsibility for the accuracy, completeness, or any third party's use or the results of such use of any information, apparatus, product, or process disclosed, or represents that its use would not infringe privately owned rights. Reference herein to any specific commercial product, process, or service by trade name, trademark, manufacturer, or otherwise, does not necessarily constitute or imply its endorsement, recommendation, or favoring by the United States Government or any agency thereof or its contractors or subcontractors. The views and opinions of authors expressed herein do not necessarily state or reflect those of the United States Government or any agency thereof.

FOR UNCLASSIFIED, UNLIMITED STI PRODUCTS

Available electronically at:

OSTI:

\section{http://www.osti.gov/bridge}

Available for a processing fee to U.S. Department of Energy and its contractors, in paper from:

U.S. Department of Energy

Office of Scientific and Technical Information

P.O. Box 62

Oak Ridge, TN 37831

Phone: (865) 576-8401

Facsimile: (865) 576-5728

E-mail: reports@adonis.osti.gov

National Technical Information Service (NTIS):

Available for sale to the public from:

U.S. Department of Commerce

National Technical Information Service

5285 Port Royal Road

Springfield, VA 22131

Phone: (800) 553-6847

Facsimile: (703) 605-6900

Online ordering: http://www.ntis.gov/ordering.htm

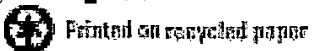




\title{
HIGH ENERGY PULSED POWER SYSTEM FOR AGS SUPER NEUTRINO FOCUSING HORN *
}

\author{
W. Zhang, J. Sandberg, W-T Weng, BNL, Upton, NY 11973, U.S.A.
}

\begin{abstract}
This paper present a preliminary design of a $300 \mathrm{kA}$, $2.5 \mathrm{~Hz}$ pulsed power system. This system will drive the focusing horn of proposed Brookhaven AGS Neutrino Super Beam Facility for Very Long Baseline Neutrino Oscillation Experiment. The peak output power of the horn pulsed power system will reach Giga-watts, and the upgraded AGS will be capable of delivering $1 \mathrm{MW}$ in beam power.
\end{abstract}

\section{INTRODUCTION}

An upgraded AGS will be able to provide a $1 \mathrm{MW}$ "Super Neutrino Beam" covering $1.0 \mathrm{GeV}$ to $7.0 \mathrm{GeV}$ wideband. It will be the proton driver for the Very Long Baseline Neutrino Program.

The physics goal of the program is to observe the oscillation pattern as a function of neutrino beam energy, covering three full oscillations yielding precise resolution of all interested parameters. A unique aspect of the BNL proposal is the ability to measure CP parameters with $v_{\mu}$ beam alone.

The main facility upgrade will include a new addition of $1.2 \mathrm{GeV}$ Super-conducting LINAC, or FFAG, a higher repetition rate of $2.5 \mathrm{~Hz}$ in AGS, and a $1.0 \mathrm{MW}$ target station and neutrino channel.

A target and the beam focusing horn system are essential components of the accelerator based neutrino facility. The $28 \mathrm{GeV}$ proton beam fi-om AGS will be transported to a graphite based carbon-carbon composite target, and large number of pions will be generated and decay into muons and neutrinos. Pulsed horns are required to focus the pion beam.

The basic requirement of horn is a $250 \mathrm{kA}$ pulsed system, and is desirable to have a system capable of 300 $\mathrm{kA}$. Hence, the design is aimed at $300 \mathrm{kA}$. Table I lists Horn/Target design parameters.

\begin{tabular}{|l|l|}
\hline Proton Beam Energy & $28 \mathrm{GeV}$ \\
\hline Protons ner Pulse & $8.9 \times 10^{13}$ \\
\hline Average Beam Current & $35.7 \mu \mathrm{A}$ \\
\hline Repetition Rate & $2.5 \mathrm{~Hz}$ \\
\hline Pulse Length & $2.58 \mu \mathrm{s}$ \\
\hline Number of Bunches & 23 \\
\hline Number of Protons per Bunch & $3.87 \times 10^{12}$ \\
\hline AGS Circumference & $807.1 \mathrm{~m}$ \\
\hline Bunch Length & $40 \mathrm{~ns}$ \\
\hline Bunch Spacing & $60 \mathrm{~ns}$ \\
\hline Normalized Emittance - X & $100 \pi \mathrm{mm}$-mrad \\
\hline Normalized Emittance - Y & $100 \pi \mathrm{mm}$-mrad \\
\hline Longitudinal Emittance & $5.0 \mathrm{eV}$-sec \\
\hline
\end{tabular}

*Work performed under auspices of U.S. Dept. of Energy.

\begin{tabular}{|l|l|}
\hline Target Material & $\begin{array}{l}\text { carbon-carbon } \\
\text { composite }\end{array}$ \\
\hline Target Diameter & $1.2 \mathrm{~cm}$ \\
\hline Target Length & $80 \mathrm{~cm}$ \\
\hline Horn Small Radius & $7 \mathrm{~mm}$ \\
\hline Beam Size (Radius) on Target & $2 \mathrm{~mm}(\mathrm{rms})$ \\
\hline Horn SmallestRadius & $6 \mathrm{~mm}$ \\
\hline Horn Large Radius & $61 \mathrm{~mm}$ \\
\hline $\begin{array}{l}\text { Horn Inner Conductor } \\
\text { Thickness }\end{array}$ & $2.5 \mathrm{~mm}$ \\
\hline Horn Minimum Thickness & $1 \mathrm{~mm}$ \\
\hline Hern Length & $217 \mathrm{~mm}$ \\
\hline Horn Peak Current & $250 \mathrm{kA}$ \\
\hline Current Repetition Rate & $2.5 \mathrm{~Hz}$ \\
\hline Power Supply Waveform & $\begin{array}{l}\text { Sinusoidal, Base } \\
\text { Width } 1.2 \mathrm{~ms}\end{array}$ \\
\hline
\end{tabular}

\section{AREA AND SYSTEMLAYOUT}

The present plan for AGS Super Neutrino Beam Facility is to use two horns at approximately 8 meters apart. The power supply will be housed in a service building $50 \mathrm{ft}$ away fi-om the target/hom area, as shown in Figure 1.

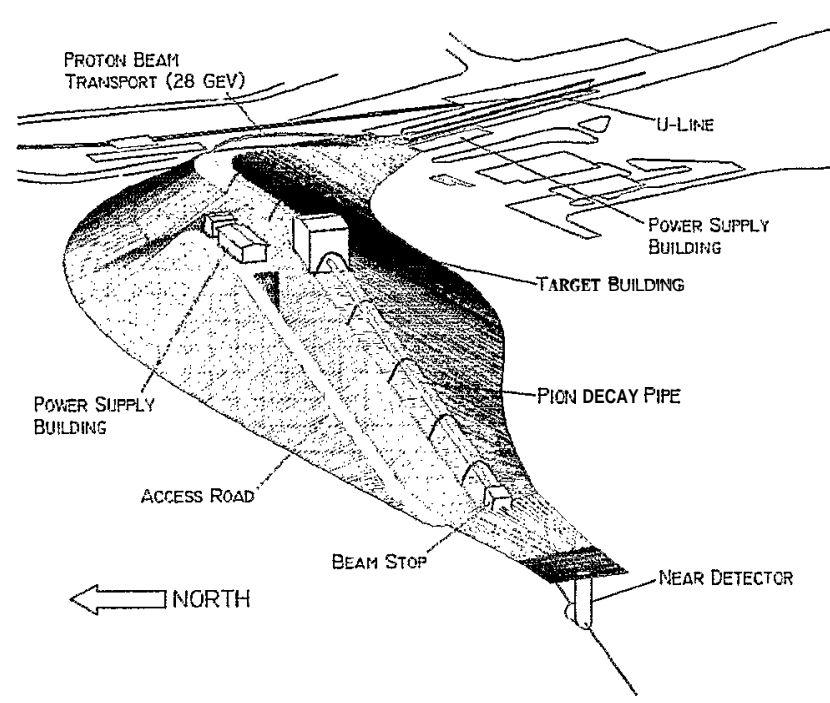

Figure 1. Target/Horn area map.

A preliminary study is being conducted to explore the key issues associated with the power supply system design. Advanced technologies used in similar systems as well as new ideas are being examined, simulated and evaluated. This power supply will be a very high stored energy, high average power, and high peak power system.

Most commonly used scheme is the capacitor discharge circuit. In this type of circuit, a capacitor bank stores the 
energy, and a main discharge switch releases the energy to the load through transmission lines. For very long distant transmission, pulsed transformers have been added into the KEK design and CNGS horn system. Figure 2 shows a simplified block diagram of a horn system.

The technical challenge is often the realization of this simple circuitry. Major technical issues include:

$\checkmark$ High voltage design;

$\checkmark$ High current transmission;

$\checkmark$ High energy storage;

$\checkmark$ High radiation environment;

$\checkmark$ Device availability;

$\checkmark$ Electrical, mechanical, and radiation safeties;

$\checkmark$ High noise immunity of control system, etc.
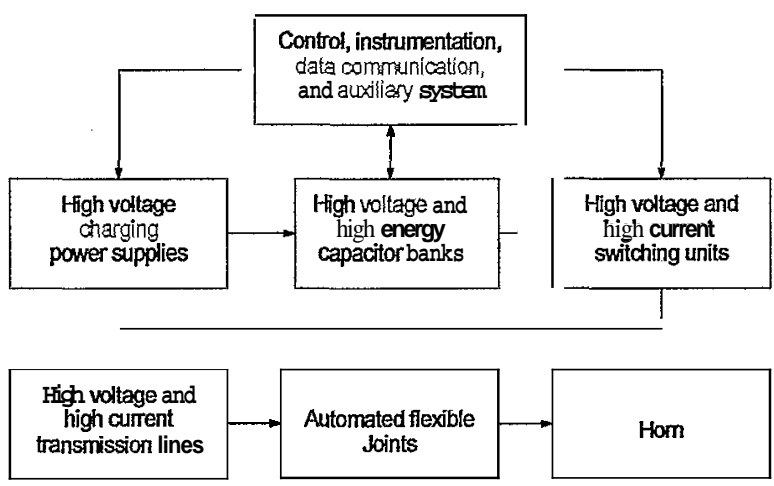

Figure 2. Simplified block diagram of horn system.

\section{CRITICAL ISSUES}

The horn as an electrical load is usually being described as an inductor in series with a resistor. Discrete parameters of inductance and resistance are also used to formulate the short length, low impedance transmission lines when associated with low bandwidth pulse. Hence, the circuit can be simplified as a RLC discharge circuit.

In the high current path, the resistance caused voltage drop and energy dissipation are critical factors to be considered. The cooling system for heat removal from the effective resistor, and the additional charging power required to make up the resistive dissipation can be very costly. Hence, the low resistance design is preferred.

\section{Resistance and Skin Effect}

The load and transmission line resistance varies with frequency due to skin effect. For any given material, the skin depth $\delta_{\mathrm{s}}$ is inverse proportional to the square root of the frequency $\mathbf{f}$, and the effective resistance $\boldsymbol{R}_{\text {eff }}$ is proportional to the oscillating frequency. Here $\delta_{s}=1 / \sqrt{\pi f \mu_{R} \mu_{o} \sigma}$, and $R_{e f f}=l / \sigma b \delta_{s}$, where $l$ is the conductor length and $\mathrm{b}$ is the conductor width. The material's conductivity, relative permeability, and the free space permeability are described by $\sigma, \mu_{\mathrm{R}}$, and $\mu_{0}$, respectively.

One can see that lower frequency leads to lower effective resistance. The other factors associated with effective resistance are the length, width, and permeability and material conductivity. For non-magnetic material, the relative permeability is close to unit. The switching device on-state resistance and hardware connection joints resistance also contribute to the total resistance.

In summary, the lower effective resistance can be achieved by using lower frequency, higher skin depth, wider conductor width, shorter conductor length, higher conductivity material, lower switch on-state resistance, and lower connectionjoint resistance.

For the 300-series aluminum being considered in the horn mechanical design, the material skin depth is 3.574 $\mathrm{mm}$ at $833 \mathrm{~Hz}$.

\section{Inductance Issue}

The total inductance includes the horn inductance, transmission line inductance, series inductance of the capacitor, switch inductance, and circuit loop stray inductance. The external inductance depends on the inductor geometry and material permeability. The internal inductance has frequency dependence.

The voltage across the inductor is $V_{L}(t)=L d I(t) / d t$. Hence, the larger inductor and faster current rate of change requires higher voltage.

The current going through the inductor is the inductively stored energy. Therefore, we have that the higher the inductance and current, the higher the capacitance and its initial voltage. For a reasonable design, the total inductance shall be kept as low as possible, and the current rise time shall be chosen to accommodate the device operating voltage.

\section{Electromigration Issue}

The electromigration phenomena are associated with very high current densities [2]. The horn system is a high current system. Horn tip, target pipe, switch connections, capacitor leads, and transmission line joints are places of potential electromigration damage. With a peak current of $300 \mathrm{kA}$, the current flow through the metallic pathway is a major concern. The transmission lines can be designed with large metal plates or large quantity of coaxial cables in parallel. All joints need to be designed with low resistance material, large conducting area, high contact pressure, and smooth conducting surface.

\section{SIMULATIONRESULTS}

Let us consider a basic system, with overall inductance of $2.5 \mu \mathrm{H}$, a horn and line resistance of $2 \mathrm{~m} \Omega$, and a capacitor bank of $16 \mathrm{mF}$. If the initial capacitor voltage is 4200 Volts, the peak output current amplitude is above $300 \mathrm{kA}$ with $314 \mu$ s rise time.

In this design, a diode is used to protect capacitor from excessive reverse voltage. Since the main switch is at on state during conversion, the current will continue flow through the output circuit and the stored energy is fully dissipate in each operating cycle. The reverse damping resistor is chosen to critically damp the current. The 
capacitor voltage waveform and the horn current waveform simulations are shown in Figure 3.

The stored energy in the capacitor is $141 \mathrm{~kJ}$, and the peak output power is above one Giga-watt. For $2.5 \mathrm{~Hz}$ pulse repetition rate, the minimum charging power supply is $352 \mathrm{~kW}$. The resistance used in the example is tight for the chosen frequency. If higher resistance has to be used, then the voltage and capacitance have to be increased accordingly.
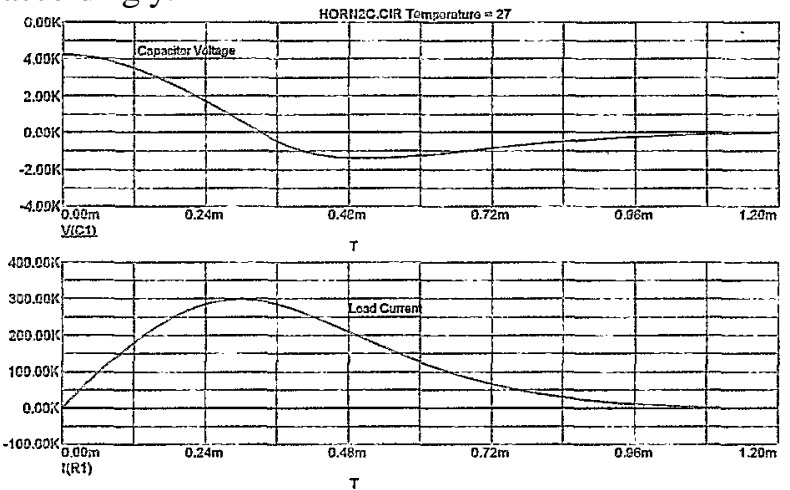

Figure 3. Capacitor voltage and horn current waveform simulations.

To minimize the resistive heat dissipation on horn, two factors may be considered. One is to reduce the horn resistance by mechanical design; another is to recover the electrical energy, as shown in Figures 4.

In this particular example, the energy recovered is about $50 \%$. However, additional active components will make the circuit more complicate and the reverse voltage on the capacitor is higher.
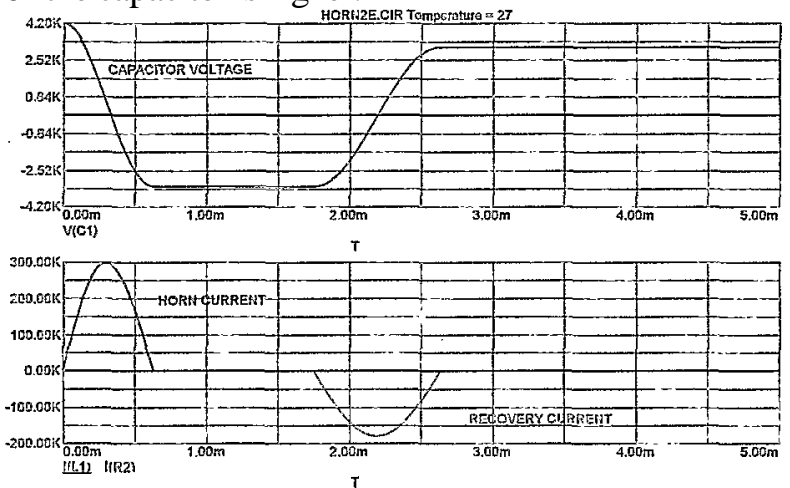

Figure 4. Horn system with recovery circuit: Capacitor voltage, horn current, and recovery current waveform simulations.

The design options of high voltage, high current pulsed system are often limited by the industry development and available components. In this case, the preferred operating voltage is less than $5 \mathrm{kV}$. The total resistance shall be kept to less than or around $2 \mathrm{~m} \Omega$.

\section{HARDWARE CONSIDERATIONS}

A typical horn power supply system occupies several tens of standard racks and weights tens of tons.
The large storage capacitance and very high stored energy, a few hundred kilo joules, make it necessary to divide the capacitors into individual cells and isolate them from each other to avoid catastrophic failure. In new and proposed designs, self-healing capacitors are being used for the fault tolerance, and increased reliability. This type of capacitor is usually rated under a few kilo-volts.

The very high current switching has to be accomplished by using multiple switches in parallel. The discharge switch in favor is the light triggered SCR. The trend of new designs is to use solid-state switch, which has much longer lifetime compared to gas discharge switches.

The low inductance and low resistance transmission line has to be made by multiple coaxial cables or planar transmission lines. Both planar and coaxial transmission lines are being considered. Planar transmission line has the advantage of ultra low resistance. Nevertheless, the open structure of the planar line is more sensitive to the condensation and ionized air at horn. Brookhaven developed rigid coaxial cables is better for higher voltage holding. Robotic arms will be used to remotely connect and disconnect transmission lines from the horn. The mechanical structure of the flexible joint of the transmission line will be a major concern.

The high voltage power supply, several hundred kilo Watts, is often multiple units in parallel sharing common control and combined as a single power source. In our situation, it makes sense to built the system with modularized approach. This topology shall provide a better output inductive isolation, higher operability and maintainability, and more flexible charging system.

\section{ACKNOWLEDGEMENT}

Authors would like to thank Mr. Ken Bourkland of FERMI Laboratory for his advice and useful discussions.

\section{REFERENCES}

[1] M. Diwan, et al., "AGS Super Neutrino Beam Facility Accelerator and Target System Design", BNL Report \#BNL -71228, April 2003.

[2] W. Zhang, s. Bellavia, J. Sandberg, N. Simos, J. Tuozzolo, W-T. Weng, "ElectromigrationIssues in High Current Horn", this conference.

[3] G. Acquistapace, J.M. Maugain, F. Voelker, "Considerations on a $75 \mathrm{~Hz}$ pulsed horn", CERN, 05, 2000.

[4] K. Bourkland, C, Jensen, D. Tinsley, "'HighCurrent Pulse Striplines", 2001 PPPS.

[5] K. Bourkland, K. Roon, D. Tinsley, “205 kA Pulse Power Supply for Neutrino Focusing Horn", 2002 PMS.

[6] G. Grawer, "Investigation of the possibility to build a $400 \mathrm{kA}$ pulse current generator to drive a magnetic horn", CERN-NUFACT Note 038, July 19,2000.

[7] J. Sandberg, et.al. "The Neutrino Horn 300 Kiloampere Pulsed Power Supply at Brookhaven National Laboratory", PAC 1987.

[8] K. Bourkland, private communication. 